\title{
PREDIKSI PENERIMAAN MAHASISWA BARU DENGAN MULTI LAYER PERCEPTRON
}

\author{
Khoirudin $^{1}$, Dewi Nurdiyah ${ }^{2}$, Nur Wakhidah ${ }^{3}$ \\ ${ }^{1,2,3}$ Jurusan Teknik Informatika, Fakultas Teknologi Informasi dan Komunikasi, Universitas Semarang \\ Jl. Soekarno-Hatta Tlogosari, Semarang 59160 \\ E-mail: ${ }^{1}$ khoirudin@usm.ac.id,nurdiyah@usm.ac.id ${ }^{2}{ }^{3}$ ida@usm.ac.id
}

\begin{abstract}
ABSTRAKS
Penerimaan mahasiswa baru adalah agenda yang rutin dijalani oleh sebuah institusi perguruan tinggi,. Jumlah penerimaan mahasiswa baru dapat meningkat atau menurun setiap tahunnya di Universitas Semarang. Oleh karenanya, perlu adanya prediksi jumlah penerimaan mahasiswa baru dengan teknologi berbasis artificial intelligent. Penelitian ini mengusulkan metode untuk memprediski jumlah penerimaan mahasiswa baru di Universitas Semarang menggunakan algoritma Multi Layer Perceptron, dengan dataset time series pendaftaran mahasiswa baru dari tahun 2008 hingga 2017. Uji coba Multi Layer Perceptron dengan arsitektur 5-9-1 menghasilkan Mean Squered Error pada data training sebesar 0.00096 dan Mean Squered Error pada data testing sebesar 0.1. Sehingga, metode yang diusulkan sangat bagus digunakan untuk prediksi penerimaan mahasiswa baru di Universitas Semarang
\end{abstract}

Kata Kunci: prediksi penerimaan mahasiswa baru, multi layer perceptron, data time series

\section{PENDAHULUAN}

Penerimaan mahasiswa baru (PMB) merupakan agenda rutin yang dilakukan oleh sebuah perguruan tinggi. Jumlah penerimaan mahasiswa baru mencerminkan bagaimana pandangan dan minat masyarakat pada perguruan tinggi tersebut. Perguruan tinggi swasta saling bersaing untuk meningkatkan jumlah penerimaan mahasiswa baru Sehingga, adakalanya jumlah penerimaan mahasiswa baru dapat meningkat ataupun menurun setiap tahunnya di Universitas Semarang. Oleh karenanya, Universitas Semarang perlu adanya perencanaan berbasis teknologi untuk memprediksi jumlah penerimaan mahasiswa baru. Hasil prediksi ini dapat dijadikan acuan oleh Humas Universitas Semarang untuk prediksi jumlah mahasiswa baru yang melakukan daftar ulang agar memenuhi target yang ditentukan.

Prediksi merupakan teknologi rekayasa pengetahuan dalam bidang artificial intelligent atau kecerdasan buatan. algoritma yang dapat digunakan untuk prediksi adalah MLP (Multi Layer Perceptron) yang merupakan salah satu jenis dari algoritma NN (Neural Network) atau Jaringan Syaraf Tiruan. Sebelumnya, Neural Network telah digunakan oleh (Syahrullah et al., 2016) untuk prediksi pendaftaran mahasiswa baru program pendidikan dasar menggunakan algoritma NN Backpropagation di UPBJJ, eksperimen dengan arsitektur NN 15-16-1 dengan fungsi aktivasi bipolar sigmoid menghasilkan MSE 19.256. (Meinanda et al., 2009) telah menggunakan algoritma MLP untuk prediksi masa studi sarjana, prediksi ini digunakan untuk mengambil kebijakan akademik untuk mencegah kasus DO (Drop Out) hasil ekperimen dengan metode yang diusulkan menunjukkan akurasi 95\%. (Simbolan, Sirait., 2015) menggunakan algoritma Jaringan Syaraf Tiruan untuk prediksi jumlah mahasiswa baru di STIMIK BUDIDARMA MEDAN. Uji coba dengan arsitektur 6-5-1 menghasilkan MSE yang kecil yaitu 0.09. Selain penetapan arsitektur MLP, performa kinerja MLP juga dipengaruhi oleh fungsi aktivasi. (Syamsiah dan Wahono, 2017) telah menggunakan algoritma Jaringan Syaraf Tiruan untuk memprediksi bahan pangan pokok di Indonesia untuk mengetahui kondisi bahan pangan pokok di Indonesia. Uji coba menggunakan arsitektur 9-6-1 dengan fungsi aktivasi tansig menghasilkan RMSE yang kecil yaitu 0.01. fungsi aktivasi tansig merupakan fungsi aktivasi sigmoid bipolar yang memiliki range -1 hingga 1 sehingga semua data yang diolah dengan MLP perlu dilakukan normalisasi. (Junaedi et al., 2011) telah mengkaji beberapa metode untuk normalisasi data. Salah satu metode yang cocok untuk normalisasi data dari range -1 hingga 1 yaitu metode Minmax. Metode Minmax merupakan metode yang mudah dan fleksibel karena hasil dapat disesuai dengan range yang ditentukan.

Berdasarkan penelitian sebelumnya, bahwa MLP dapat menghasilkan error yang minimal. Sehingga penelitian ini mengusulkan metode prediksi penerimaan mahasiswa baru yang melakukan daftar ulang menggunakan algoritma 
MLP dengan dataset time series penerimaan

\section{METODE}

Metode eksperimen diterapkan pada penelitian ini untuk menguji performa MLP dalam memprediksi penerimaan mahasiswa baru yang melakukan daftar ulang. Gambar 1 menunjukkan

langkah-langkah metode yang digunakan dalam penelitian ini

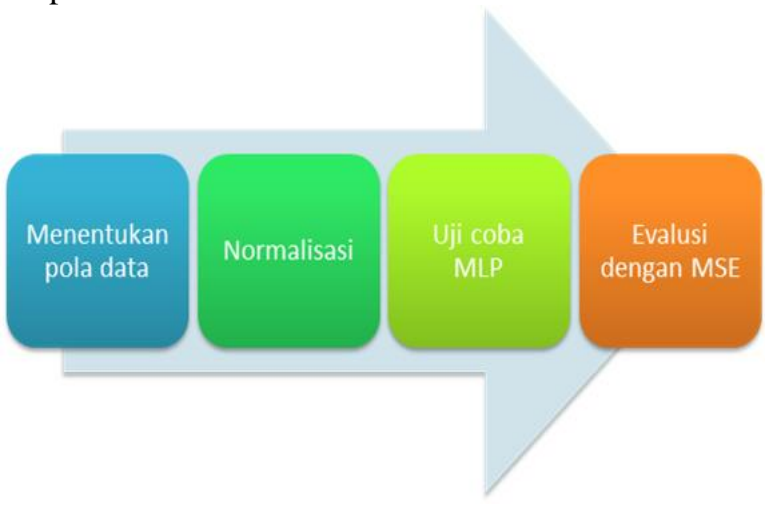

Gambar 1. Metode yang diusulkan

\subsection{Menentukan pola data}

Penetapan pola data digunakan untuk menentukan variabel bebas dan variabel terikat. Variabel bebas adalah variabel yang keberadaanya tidak dipengaruhi oleh variabel yang lain. Sedangkan variabel terikat adalah varibel yang dipengaruhi oleh variabel lain atau variabel yang menjadi target. Penentuan pola berdasarkan dataset time series penerimaan mahasiswa baru dari tahun 2008 hingga 2017 ditunjukkan pada tabel 1 .

Tabel 1. Dataset time series penerimaan mahasiswa baru

\begin{tabular}{ccccc}
\hline $\begin{array}{c}\boldsymbol{N} \\
\boldsymbol{O}\end{array}$ & Tahun & Target & Daftar & $\begin{array}{c}\text { Daftar } \\
\text { Ulang }\end{array}$ \\
\hline 1 & 2008 & 785 & 1045 & 667 \\
\hline 2 & 2009 & 975 & 1169 & 883 \\
\hline 3 & 2010 & 1134 & 1321 & 1024 \\
\hline 4 & 2011 & 1196 & 1349 & 1086 \\
\hline 5 & 2012 & 1255 & 1500 & 1148 \\
\hline 6 & 2013 & 1374 & 1672 & 1678 \\
\hline 7 & 2014 & 1734 & 2214 & 1718 \\
\hline 8 & 2015 & 1695 & 2148 & 1579 \\
\hline 9 & 2016 & 1600 & 2235 & 1685 \\
\hline 10 & 2017 & 1595 & 2094 & 1499 \\
\hline
\end{tabular}

Variabel target menunjukkan target jumlah mahasiswa baru yang melakukan daftar ulang, variabel daftar adalah calon mahasiswa yang mendaftar. Sedangkan variabel daftar ulang mahasiswa baru dari tahun 2008 hingga 2017. adalah mahasiswa baru yang melakukan daftar ulang.

\subsection{Normalisasi}

Normalisasi data digunakan untuk mentransformasikan data penerimaan mahasiswa baru menjadi range baru. Pada penelitian ini metode normalisasi yang digunakan adalah normalisasi Minmax. Rumus metode Minmax

$$
\begin{aligned}
v^{\prime}= & \frac{v-\min _{A}}{\max _{A}-\min _{A}}\left(\text { new_max } \max _{A}-\text { new_ }_{-} \min _{A}\right) \\
& +n e w_{-} \min _{A}
\end{aligned}
$$

$\mathrm{v}^{\prime}=$ data baru hasil normalisasi, $\mathrm{v}=$ data asli, $\min \mathrm{A}=$ minimum data asli pada array-nya, maxA = maximum data asli pada array-nya, new_maxA = maksimum data baru, new_minA $=$ minimum data baru

\subsection{Multi Layer Perceptron}

MLP merupakan salah satu algoritma Neural Network yang melakukan pembelajaran feedforward atau maju mundur. MLP memliki tiga layer yaitu input layer, hidden layer dan output layer. Berikut langkah-langkah algoritma MLP :

1. Inisiasi bobot, dapat menggunakan bobot acak dengan range antara 0 hingga 1

2. Inisiasi bias, dapat menggunakan bias acak dengan range antara 0 hingga 1

3. Menghitung besarnya input dari input layer menuju hidden layer dengan rumus

$$
\text { Input }_{j}=\sum_{i=1}^{n} O_{i} w_{i j}+\bar{\theta}_{j}^{-}
$$

$O i=$ Output simpul $i$ dari layer sebelumnya, wij $=$ bobot relasi dari simpul $i$ pada layer, sebelumnya ke simpul $j, \theta j=$ bias (sebagai pembatas)

4. Berdasarkan langkah 3, selanjutnya melakukan pembangkitan output dari hidden layer menuju output layer. Dengan menggunakan fungsi aktivasi tansig atau sigmoid bipolar

$$
f(\text { net })=\frac{2}{1+e^{-n e t}}-1
$$

5. Hitung nilai Error antara yang diprediksi dengan nilai sesungguhnya, dengan rumus 
Error $_{j}=$ Output $_{j} \cdot\left(1-\right.$ Output $\left._{j}\right) \cdot\left(\right.$ Target $_{j}-$ Output $\left._{j}\right)$

Outputj $=$ Output aktual dari simpul $j$, Target $j=$ Nilai target yang sudah diketahui pada data training

6. Setelah nilai error dihitung, selanjutnya kembali ke layer sebelumnya, untuk menghitung error pada hidden layer dengan rumus

$$
\text { Error }_{j}=\text { Output }_{j}\left(1-\text { Output }_{j}\right) \sum_{k=1}^{n} \text { Error }_{k} w_{j k}
$$

Outputj $=$ Output aktual dari simpul j, Errork $=$ error simpul $k$ wjk $=$ Bobot relasi dari simpul $j$ $\mathrm{ke}$, simpul $k$ pada layer berikutnya

7. Nilai error sebelumnya digunakan untuk memperbaiki bobot

$$
w_{i j}=w_{i j}+l \cdot \text { Error }_{j} \cdot \text { Output }_{i}
$$

$w i j=$ bobot relasi dari unit $i$ pada, layer sebelumnya ke unit $j, l=$ learning rate (konstanta, nilainya antara 0 sampai dengan 1.

8. Iterasi MLP akan berhenti jika sudah memenuhi maksimal epoch yang ditentukan atau memenuhi mse yang ditentukan atau error bernilai 0 .

\subsection{Evaluasi dengan MSE}

Mean Squared Error (MSE) merupakan pengukuran error untuk keseluruhan data yang diuji. Rumus MSE sebagai berikut

$$
\text { MSE : } \frac{\sum_{t=1}^{n}(X t-S t)^{2}}{n}
$$

$\mathrm{Xt}=$ nilai data aktual pada periode ke-t, $\mathrm{St}=$ nilai hasil peramalan pada periode $\mathrm{ke}-\mathrm{t}, \mathrm{t}=$ periode peramalan, $\mathrm{n}=$ banyaknya data

\section{HASIL DAN PEMBAHASAN}

Berdasarkan daftar peneriaman mahasiswa yang ditunjukkan di tabel 1 merupakan dataset time series. yang berarti bahwa data pada tahuntahun sebelumnya $(\mathrm{t}-1, \mathrm{t}-2 \ldots . \mathrm{t}-\mathrm{n})$ dapat berdampak pada tahun sekarang yaitu tahun ke-t. Karena data penerimaan mahasiswa baru merupakan data time series maka variabel pada tahun sebelumnya (t-1)(dapat menjadi variabel bebas pada tahun ke-t. łada penelitian ini tahun sebelumnya adalah t-1 yang berarti data pada 1 tahun sebelumnya dapat mempengaruhi data pada tahun sekarang (t). Sehingga didapatkan pola seperti tabel 2 .

Tabel 2. Pola dataset

\begin{tabular}{cccccc}
\hline $\begin{array}{l}\text { Targe } \\
\boldsymbol{t}(\boldsymbol{t}-\mathbf{1})\end{array}$ & $\begin{array}{l}\text { Daftar } \\
(\boldsymbol{t}-\mathbf{1})\end{array}$ & $\begin{array}{l}\text { Daftar } \\
\text { Ulang }(\boldsymbol{t}-\mathbf{1} \\
\mathbf{1})\end{array}$ & $\begin{array}{l}\text { Targ } \\
\boldsymbol{e t}(\boldsymbol{t})\end{array}$ & $\begin{array}{l}\text { Dafta } \\
\boldsymbol{r}(\boldsymbol{t})\end{array}$ & $\begin{array}{l}\text { Daftar } \\
\text { Ulang }(\boldsymbol{t})\end{array}$ \\
\hline$X 1$ & $X 2$ & $X 3$ & $X 4$ & $X 5$ & $Y$ \\
\hline 785 & 1045 & 667 & 975 & 1169 & 883 \\
\hline 975 & 1169 & 883 & 51134 & 1321 & 1024 \\
\hline 1134 & 1321 & 1024 & 1196 & 1349 & 1086 \\
\hline 1196 & 1349 & 1086 & 1255 & 1500 & 1148 \\
\hline 1255 & 1500 & 1148 & 1374 & 1672 & 1678 \\
\hline 1374 & 1672 & 1678 & 1734 & 2214 & 1718 \\
\hline 1734 & 2214 & 1718 & 1695 & 2148 & 1579 \\
\hline 1695 & 2148 & 1579 & 1600 & 2235 & 1685 \\
\hline 1600 & 2235 & 1685 & 1595 & 2094 & 1499 \\
\hline
\end{tabular}

$\mathrm{X} 1, \mathrm{X} 2, \mathrm{X} 3, \mathrm{X} 4$ dan X5 merupakan variabel bebas, dan $\mathrm{Y}$ adalah variabel terikat atau target. Kemudian, dataset pada dari tabel 2 dibagi menjadi 2 yaitu $70 \%$ untuk data training dan $30 \%$ untuk data testing. Setelah itu dilakukan normalisasi dengan metode Minmax dengan range -1 hingga 1 . Pembatasan range ini berdasarkan dari fungsi aktivasi tansig atau sigmoid biner. Hasil normalisai ditunjukkan pada tabel 3 .

Tabel 3. Hasil normalisai dataset dengan metode minmax

\begin{tabular}{cccccc}
\hline $\begin{array}{l}\text { Target } \\
(\boldsymbol{t}-\mathbf{1})\end{array}$ & $\begin{array}{l}\text { Daftar } \\
(\boldsymbol{t}-\mathbf{1})\end{array}$ & $\begin{array}{l}\text { Daftar } \\
\text { Ulang } \\
(\boldsymbol{t}-\mathbf{1})\end{array}$ & $\begin{array}{l}\text { Target } \\
(\boldsymbol{t})\end{array}$ & $\begin{array}{l}\text { Daftar } \\
(\boldsymbol{t})\end{array}$ & $\begin{array}{l}\text { Daftar } \\
\text { Ulang } \\
(\boldsymbol{t})\end{array}$ \\
\hline$X 1$ & $X 2$ & $X 3$ & $X 4$ & $X 5$ & $Y$ \\
\hline-1.0000 & -1.0000 & -1.0000 & -1.0000 & -1.0000 & -1.0000 \\
\hline-0.3548 & -0.6045 & -0.5727 & -0.5810 & -0.7091 & -0.6623 \\
\hline 0.1851 & -0.1196 & -0.2938 & -0.4177 & -0.6555 & -0.5138 \\
\hline 0.3956 & -0.0303 & -0.1711 & -0.2622 & -0.3665 & -0.3653 \\
\hline 0.5959 & 0.4514 & -0.0485 & 0.0514 & -0.0373 & 0.9042 \\
\hline 1.0000 & 1.0000 & 1.0000 & 1.0000 & 1.0000 & 1.0000 \\
\hline 1.0000 & 0.5172 & 1.0000 & 1.0000 & -0.2340 & -0.1398 \\
\hline 0.4179 & -1.0000 & -1.0000 & -0.9000 & 1.0000 & 1.0000 \\
\hline-1.0000 & 1.0000 & 0.5252 & -1.0000 & -1.0000 & -1.0000 \\
\hline
\end{tabular}

Dataset hasil normalisasi pada tabel 4 digunakan untuk sebagai masukan MLP, pada penelitian ini epoch, learning rate, momentum yang digunakan adalah default. 1000 epoch, 0.1 learning rate dan 0.95 momentum. Sedangkan untuk arsitektur MLP yang diperlukan adalah penentuan jumlah neuron untuk layer input, penentuan jumlah neuron untuk hidden layer dan penentuan jumlah neuron untuk output layer. Berdasarkan tabel 4.2 bahwa terdapat 5 variabel bebas yaitu taget ( $\mathrm{t}-1)$, daftar ( $\mathrm{t}-1)$, daftar ulang $(\mathrm{t}-1)$, target $(\mathrm{t})$, daftar $(\mathrm{t})$ sehingga terdapat lima 
input layer dan 1 hidden layer yaitu variabel daftar ulang (t). Pada penelitian ini dilakukan uji coba berulang-ulang untuk hidden layer ditunjukkan pada tabel 4 .

Tabel 4. Hasil uji coba MLP

\begin{tabular}{c|ccl}
\hline $\begin{array}{c}\text { Percobaan } \\
\text { Ke- }\end{array}$ & $\begin{array}{c}\text { Arsitektur MLP } \\
\text { input-hidden- } \\
\text { output }\end{array}$ & $\begin{array}{l}\text { MSE } \\
\text { training }\end{array}$ & $\begin{array}{l}\text { MSE } \\
\text { Testing }\end{array}$ \\
\hline 1 & $5-9-1$ & 0.00097 & 0.8 \\
2 & $5-9-1$ & 0.00098 & 1.04 \\
3 & $5-9-1$ & 0.00096 & 0.1 \\
4 & $5-6-1$ & 0.0008 & 2.52 \\
5 & $5-6-1$ & 0.00093 & 1.2 \\
6 & $5-6-1$ & 0.00099 & 2.52 \\
7 & $5-12-1$ & 0.00096 & 1.78 \\
8 & $5-12-1$ & 0.00098 & 1.63 \\
9 & $5-12-1$ & 0.00099 & 1.24 \\
\hline
\end{tabular}

Dari tabel 4.4 percobaan ke-3 dengan arsitektur 5-9-1 seperti pada gambar 2, berhenti pada epoch ke-125 dengan mse yang kecil pada data training yaitu 0.00096 sehingga dapat menghasil mse yang kecil pula pada data testing yakni 0.1

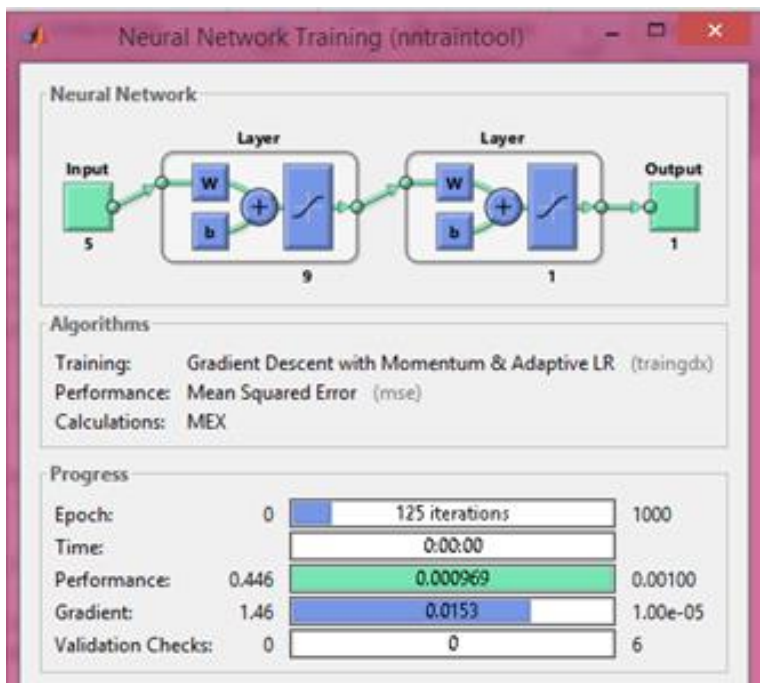

Gambar 2. Arsitektur MLP 5-9-1

Sehingga, 5-9-1 merupakan model MLP yang ideal untuk prediksi jumlah mahasiswa yang melakukan daftar ulang.

\section{KESIMPULAN}

Berdasarkan hasil dari eksperimen, Neural Network dengan arsitektur 5-9-1 merupakan arsitektur terbaik untuk memprediksi jumlah penerimaan mahasiswa baru universitas semarang. Dari hasil uji coba metode ini dapat menghasilkan MSE yang paling minimal yaitu 0.1. Sehingga, metode ini dapat digunakan sebagai alternatif untuk solusi penetapan target penerimaan mahasiswa baru. oleh Humas Universitas Semarang.

\section{PUSTAKA}

H. S. \& Sirait, M. J. F., 2015. Implementasi Jaringan Syaraf Tiruan Dalam. Pelita Informatika Budi Darma, 9(2).

Junaedi, H., Budianto, H., Maryati, I., Melani, Y., 2011. Data Transformation Pada Data Mining. Surabaya Ideatech2011.

Lesnussa, Y. A., Latuconsina, S. \& Persulessy, E. R., 2015. Aplikasi Jaringan Saraf Tiruan Backpropagation Untuk Memprediksi Prestasi Siswa Sma (Studi Kasus: Prediksi Prestasi Siswa Sman 4 Ambon). Jurnal Matematika Integratif, 11(2), Pp. 159-160.

Meinanda, M. H., Annisa, M., Muhandri, N. \& Suryadi, K., 2009. Prediksi Masa Studi Sarjana Dengan Artificial Neural Network. Internetworking Indonesia Journal, 1(2).

Prasetya, R., 2017. Implementasi Jaringan Syaraf Tiruan Backpropagation Untuk Memprediksi Ketinggian Air (Studi Kasus: Sungai Ciliwung). String Satuan Tulisan Ris. Dan Inov. Teknol. 1.

Setiadi, A., 2012. Penerapan Algoritma Multilayer Perceptron Untuk Deteksi Dini Penyakit Diabetes. Paradigma, Maret, 14(1), Pp. 46-59.

Solikhun, S., Safii, M., Trisno, A., 2017. Jaringan Saraf Tiruan Untuk Memprediksi Tingkat Pemahaman Sisiwa Terhadap Matapelajaran Dengan Menggunakan Algoritma Backpropagation. J-Sakti J. Sains Komput. Dan Inform. 1, 24-36.

Syahrullah, S., Ngemba, H.R., Hendra, S., 2016. Pendaftaran Mahasiswa Baru Program Pendidikan Dasar Menggunakan Algoritma Nn Backpropagation Di Upbjj-Universitas Terbuka Provinsi Sulawesi Tengah. Semnasteknomedia Online 4, 4-9.

Syamsiah, N. O. \& Wahono, R. S., 2017. Penerapan Jaringan Syaraf Tiruan Backpropagation Dalam Prediksi Produksi Bahan Pangan Pokok Di Indonesia. JURNAL TEKNIK INFORMATIKA, Februari.3(1).

Yusran, 2016. Implementasi Jaringan Syaraf Tiruan (Jst) Untuk Memprediksi. Jurnal Ipteks Terapan Research Of Applied Science And Education, Volume Kopertis Wilayah X, Pp. 269-275. 